\title{
Characterization of Genetic and Biochemical Mechanisms of Fludioxonil and Pyrimethanil Resistance in Field Isolates of Penicillium digitatum
}

\author{
L. Kanetis, H. Förster, C. A. Jones, K. A. Borkovich, and J. E. Adaskaveg
}

First, third, fourth, and fifth authors: Department of Plant Pathology, University of California, Riverside 92521; and second author: Department of Plant Pathology, University of California, Davis 95616.

Accepted for publication 18 September 2007.

\begin{abstract}
Kanetis, L., Förster, H., Jones, C. A., Borkovich, K. A., and Adaskaveg, J. E. 2008. Characterization of genetic and biochemical mechanisms of fludioxonil and pyrimethanil resistance in field isolates of Penicillium digitatum. Phytopathology 98:205-214.

Genetic and biochemical mechanisms of fludioxonil and pyrimethanil resistance in isolates of Penicillium digitatum were evaluated and compared to those characterized in other fungi. Resistant isolates were naturally occurring in packinghouses and were not associated with crop losses. For the phenylpyrrole fludioxonil, $\mathrm{EC}_{50}$ values were 0.02 to $0.04 \mu \mathrm{g} / \mathrm{ml}$ for sensitive, 0.08 to $0.65 \mu \mathrm{g} / \mathrm{ml}$ for moderately resistant (MR), and $>40 \mu \mathrm{g} / \mathrm{ml}$ for highly resistant (HR) isolates. Two fludioxonilsensitive isolates evaluated were also significantly more sensitive to the unrelated dicarboximide fungicide iprodione, that also disrupts osmotic regulation, than the MR and HR isolates. There was no consistent relationship, however, between the HR and MR isolates and their sensitivity to iprodione or osmotic stress. Although, two nucleotide substitutions were found in a sequence analysis of the $\mathrm{N}$-terminal amino acid repeat region of the $o s-1$-related histidine kinase gene among isolates of $P$. digitatum, these were not correlated with fludioxonil resistance. In mycelia not

in the HR isolate. An increase in PdOS-2 was observed for sensitive and resistant isolates after exposure to fludioxonil. In addition, glycerol content in untreated mycelia of the fludioxonil-sensitive isolate was significantly higher than in resistant isolates. After exposure to fludioxonil, glycerol concentrations significantly increased in the sensitive and MR isolates, but not in the HR isolate. Thus, our studies indicate that the mode of action of fludioxonil in $P$. digitatum is probably the mitogenactivated protein kinase pathway that stimulates glycerol synthesis in sensitive and MR isolates. The general suppression of this pathway in resistant isolates was supported by the fact that growth and sporulation of MR and HR isolates were significantly reduced from that of sensitive isolates. In studies on the mode of action of anilinopyrimidines (AP), $\mathrm{EC}_{50}$ values for mycelial growth of $P$. digitatum and the previously characterized Botrytis cinerea were determined for cyprodinil and pyrimethanil using a defined culture medium without and with the addition of selected amino acids and homocysteine. The addition of amino acids resulted in a reduced toxicity of the two AP fungicides in both fungi, but the effect of each additive was significantly lower for $P$. digitatum than for $B$. cinerea. This suggests that methionine biosynthesis is not the primary target site of APs in P. digitatum.
\end{abstract} exposed to fludioxonil, the amount of phosphorylated OS-2-related protein (PdOS-2) was higher in fludioxonil-sensitive isolates and lowest
Additional keywords: citrus green mold, fungicide resistance.
Citrus green mold, caused by Penicillium digitatum (Pers.:Fr.) Sacc., is the most important postharvest disease of citrus in arid production areas, and can cause significant economic losses to citrus growers and packers. Applications of effective fungicides soon after harvest can dramatically reduce and inhibit early infections, and thus, their use is an inextricable part of disease management. The nonsimultaneous introduction and continuous use of sodium $o$-phenylphenate, thiabendazole (TBZ), and imazalil in the past, however, has resulted in the selection and spread of resistant isolates of the pathogen, with biotypes exhibiting double or even triple-resistance, rendering the fungicides' usage problematic $(4,9,21,31)$. In 2005 , fludioxonil and pyrimethanil received federal registration for postharvest use on citrus in the United States and registration for azoxystrobin is pending. The near simultaneous introduction of these three new highly efficacious fungicides against $P$. digitatum that belong to different chemical classes, will define a new era of postharvest disease management for the citrus industry (29).

Fludioxonil, a phenylpyrrole fungicide, is a nonsystemic analogue of the antibiotic pyrrolnitrin and has been commercially

Corresponding author: J. E. Adaskaveg; E-mail address: jim.adaskaveg@ucr.edu

doi:10.1094/PHYTO-98-2-0205

(C) 2008 The American Phytopathological Society available in crop protection since the mid-1990s to control a broad spectrum of plant pathogenic fungi in seed, foliar, and postharvest applications $(10,11,17)$. Pyrimethanil, an anilinopyrimidine fungicide, has been used since the early 1990s for the control of Botrytis spp. on a wide variety of crops and of Venturia inaequalis on apples and pears (39). Although both fungicides have not yet been widely used by the citrus industry, we previously obtained isolates of $P$. digitatum that were less sensitive to fludioxonil or pyrimethanil in citrus packinghouse samplings $(27,28)$ and recently, pyrimethanil-resistant isolates were obtained by others from orchards (31). No practical resistance to fludioxonil has been reported to date in field populations of any plant pathogen where the fungicide has been applied. Cases of reduced performance of anilinopyrimidines due to resistance development have been reported for $B$. cinerea on grapes $(19,34)$. Genetic studies and shifts in population dynamics towards lower sensitivities after short periods of usage underlined the single mode of action of this class of fungicides $(19,27)$.

For both fungicide classes, the mode of action and mechanisms of fungicide resistance have been extensively studied in either laboratory-induced mutants or field isolates of several fungi. Studies with B. cinerea, Fusarium sulphureum, and Neurospora crassa suggested that phenylpyrroles stimulate synthesis of polyols such as glycerol and mannitol in fungal cells, inducing germ tube distortions, abnormal hyphal swelling, and cell lysis 
$(24,43,46)$. Because glycerol accumulation is also associated with the adaptation to elevated osmotic conditions, phenylpyrroles have been proposed to mimic osmotic stress response $(46,52)$. Isolates resistant to the dicarboximide iprodione, representing another class of fungicides, were also found to be sensitive to hyperosmotic conditions and, in addition, were resistant to phenylpyrroles $(6,14,16,41,45,51)$. Therefore, it was speculated that these two classes of fungicides share a common biochemical mode of action that was related to the osmoregulation of fungal cells.

Studies using dicarboximide-resistant laboratory mutants of Ustilago maydis suggested that protein kinase and associated signal transduction pathways might be involved in the mode of action of dicarboximides (44). Also, Pillonel et al. (46) suggested that a cAMP-independent protein kinase (PK-III) may be involved in fludioxonil resistance in the model saprophytic fungus $N$. crassa. Recent advances in the understanding of osmoregulation in $N$. crassa indicated that several osmotic sensitivity $(o s)$ loci (os-1, os-4,os-5, and $o s-2)$ determined sensitivity to phenylpyrrole and dicarboximide fungicides $(14,23,42,52)$. These studies showed that $o s-1$ encodes an osmosensor two-component histidine kinase (HK) gene that regulates a downstream hierarchical mitogen activated protein (MAP) kinase phosphorylation cascade consisting of OS-4, OS-5, and OS-2, resulting in glycerol synthesis to counteract the elevated external osmotic pressure exerted on the fungal cells.

It has been shown that the mutation of os genes leads to resistance to phenylpyrrole and dicarboximide fungicides and to inhibition of glycerol synthesis $(14,15,42,52)$. As revealed by DNA sequence analyses, diverse mutational changes mainly at the $\mathrm{N}$-terminal region of $o s-1$ resulted in polymorphic phenotypes of osmotic sensitivity and in multiple resistance to both classes of fungicides. Similar results have been reported in plant pathogenic fungi such as Alternaria alternata, A. brassicicola, B. cinerea, and Monilinia fructicola $(2,8,37)$. In addition, in highly resistant $o s-2, o s-4$, and $o s-5$ mutants, neither fludioxonil nor iprodione significantly induce glycerol biosynthesis (14). Analysis of $o s-2$ and homologue mutants of Colletotrichum lagenarium, $N$. crassa, and Aspergillus nidulans suggest that this MAP kinase is essential for survival under elevated osmotic conditions $(16,32,52)$. It has been suggested by Zhang et al. (52) that phenylpyrrole fungicides might exert their fungicidal activity by over-stimulating the OS-2 MAP kinase pathway.

Biochemical and physiological studies with mepanipyrim and pyrimethanil, two members of the anilinopyrimidine class of fungicides, have suggested a reduced secretion of fungal enzymes that are involved in host cell lysis as a mechanism of action $(7,39,40)$. Other studies, however, came to the conclusion that cyprodinil and pyrimethanil inhibit the biosynthesis of methionine and other amino acids. Thus, Masner et al. (38) reported the reversal of cyprodinil inhibition in $B$. cinerea by the addition of three sulfur-containing amino acids (i.e., L-methionine, L-cystine, and L-cysteine) or DL-homocysteine, a direct precursor of methionine, with the most pronounced effects resulting from methionine and homocysteine. Furthermore, other enzymes involved in methionine biosynthesis, like cystathionine $\beta$-lyase and cystathionine $\gamma$-synthase, have been suggested as potential targets of the anilinopyrimidine fungicides $(13,35)$. Consequently, the mode of action of this class of fungicides remains unclear.

The objectives of this study were to evaluate genetic and biochemical mechanisms of fludioxonil and pyrimethanil resistance in isolates of $P$. digitatum and compare these with those characterized in other fungi. Using fludioxonil-sensitive and -resistant field isolates (naturally-occurring), we compared their sensitivities to iprodione and to osmotic stress induced by sodium chloride; we characterized the N-terminal amino acid repeat region of an OS-1 two-component HK homologous gene (PdOS1) to investigate the possibility that $\mathrm{Pdos}-1$ mutations are re- sponsible for resistance in this pathogen; and following exposure to fludioxonil, we quantified OS-2 related MAP kinase activity in protein extracts and the accumulation of glycerol to determine if the glycerol biosynthesis pathway is involved in fludioxonil resistance. For anilinopyrimidines, we investigated interactions of methionine and other sulfur-containing amino acids, as well as homocysteine, with the inhibitory effect of pyrimethanil and cyprodinil on growth of $P$. digitatum and $B$. cinerea.

\section{MATERIALS AND METHODS}

Fungal isolates and chemicals used. Fludioxonil-sensitive isolates of $P$. digitatum ( $\mathrm{Pd}$ and 2152) were collected from citrus groves and -resistant isolates (1HR, 2MR, 7MR, 12MR, 13HR, and $15 \mathrm{HR}$ ) were collected in citrus packinghouses in California. Isolates were single-spored and were maintained in sterile distilled water as mycelial plugs on potato dextrose agar (PDA; Difco Laboratories, Detroit, MI) at $4^{\circ} \mathrm{C}$. For conidial production, $P$. digitatum isolates were grown on PDA, whereas, a $B$. cinerea (Bc) isolate from strawberry was cultured on Kings B medium (1). An N. crassa wild type (WT) and an os-2 mutant strain (OS2) were maintained on Vogel's minimal medium (50) at $30^{\circ} \mathrm{C}$. Formulated products of fludioxonil (Scholar 50WP; Syngenta Crop Protection, Greensboro, NC), cyprodinil (Vangard 75WP; Syngenta Crop Protection), iprodione (Rovral 4F; Bayer CropScience, Research Triangle Park, NC), and pyrimethanil (Penbotec 400SC; Janssen Pharmaceutica, Titusville, NJ; or Scala 400SC; Bayer CropScience) were used as aqueous solutions. Technical grade fludioxonil (Syngenta Crop Protection) was prepared in dimethyl sulfoxide (DMSO).

Fungal growth, sporulation, and sensitivity of isolates of $P$. digitatum to fludioxonil, iprodione, and osmotic stress. To compare growth rates, PDA plates were inoculated with mycelial plugs of each isolate and cultures were grown for 5 days at $25^{\circ} \mathrm{C}$. Radial growth was measured daily and growth rates were determined as average growth per day over the 5-day period. There were three replicate plates per isolate and the experiment was done twice. The degree of sporulation of each isolate was rated as low, medium, or high where low equaled no or negligible sporulation and high equaled fruit completely green and fungal sporulation over the entire surface. Effective concentrations that inhibited mycelial growth by $50 \%\left(\mathrm{EC}_{50}\right.$ values) of isolates of $P$. digitatum $(\mathrm{Pd}, 2152,1 \mathrm{~S}, 2 \mathrm{~S}, 7 \mathrm{~S}, 12 \mathrm{~S}, 13 \mathrm{~S}$, and $15 \mathrm{~S})$ by fludioxonil were determined using the spiral gradient dilution (SGD) method as described previously using conidia as fungal inoculum $(12,30)$. Stock concentrations for the fludioxonil-resistant isolates were 1,000 and $5,000 \mu \mathrm{g} / \mathrm{ml}$, and $50 \mu \mathrm{g} / \mathrm{ml}$ was used for the sensitive isolates. Fungicide solutions were applied to $15-\mathrm{cm}$ PDA plates using a spiral plater (Autoplate 4000; Spiral Biotech Norwood, MA) set for the exponential deposition mode. Mycelial growth was measured after 3 days of incubation at $25^{\circ} \mathrm{C}$. This experiment was performed three times.

In experiments to determine in vitro sensitivities to fludioxonil, as well as to iprodione and osmotic stress, PDA plates $(6 \mathrm{~cm}$ in diameter) were amended with 0.1 or $10 \mu \mathrm{g} / \mathrm{ml}$ of fludioxonil, 1 , 10 , or $25 \mu \mathrm{g} / \mathrm{ml}$ of iprodione, and 10 or $40 \mathrm{~g} /$ liter of sodium chloride. The plates were then inoculated with 20 - $\mu$ l droplets of conidial suspensions $\left(1 \times 10^{6} \mathrm{conidia} / \mathrm{ml}\right)$. Three replicate plates were used for each treatment. Cultures were incubated for 4 days at $25^{\circ} \mathrm{C}$ and radial growth of the fungal colonies was determined. Growth on the amended plates was expressed as percentage of growth on the nonamended plates. This experiment was performed three times.

Sequence analysis of the $\mathrm{N}$-terminal amino acid repeat region of Pdos- 1 from isolates of $\boldsymbol{P}$. digitatum. For DNA extraction, cultures were grown in test tubes with $10 \mathrm{ml}$ of potato dextrose broth (PDB) (Difco Laboratories) for 4 to 5 days at $25^{\circ} \mathrm{C}$ and DNA was extracted as described in Judelson (26). For ampli- 
fication of the $o s-1$ homologous $P$. digitatum HK genomic region Pdos-1, the forward primer HKFwd [5'-AAGGCCAACGAG$\mathrm{GCCTT}(\mathrm{C} / \mathrm{T}) \mathrm{CA}(\mathrm{A} / \mathrm{G}) \mathrm{AA}(\mathrm{A} / \mathrm{G}) \mathrm{GC}]$ and the reverse primers HKRev1 [5'-TGCGGGTCATGGAGCC(A/G)TC(A/G/C/T)GC(C/T)TG-3'] and HKRev2 [5'-CTCGCCGTGCTCGGT(A/G)AA(C/T)TT(A/G/T)AT] were used as described by Dry et al. (8). The resultant nucleotide fragment, approximately $2 \mathrm{~kb}$ in size, was used to design the $P$. digitatum-specific primers PdFwd (5'TTTGCGTGAAATTGGTGGT) and PdRev (5'-TCATCGGCGTCCTGATCT). Polymerase chain reaction (PCR) amplifications were performed in a total volume of $25 \mu \mathrm{l}$ containing $1 \mu \mathrm{l}$ of DNA, $2 \mu \mathrm{l}$ of dNTPs (2.5 mM each dNTP), $2.5 \mu \mathrm{l}$ of PCR buffer (New England BioLabs, Inc., Ipswich, MA), $0.25 \mu$ l of bovine serum albumine $(10 \mathrm{mg} / \mathrm{ml}$; Sigma-Aldrich Inc., St. Louis, MO), $1 \mu \mathrm{l}$ of each primer $(10 \mu \mathrm{M})$, and $0.25 \mu \mathrm{l}$ of Taq polymerase (New England BioLabs, Inc.). Amplifications were performed in a PCT100 Programmable Thermal Controller (MJ Research Inc., Watertown, MA) programmed as follows: $2 \mathrm{~min}$ at $94^{\circ} \mathrm{C}$, followed by 35 cycles of $30 \mathrm{~s}$ at $94^{\circ} \mathrm{C}, 30 \mathrm{~s}$ at $65^{\circ} \mathrm{C}$, and $3 \mathrm{~min}$ at $68^{\circ} \mathrm{C}$, and a final extension at $68^{\circ} \mathrm{C}$ for $10 \mathrm{~min}$.

PCR products were visualized in $1.5 \%$ agarose gels after ethidium bromide staining, purified using ExoSAP-IT (USB Corporation, Cleveland, $\mathrm{OH}$ ), and sequenced at the Core Instrumentation Facility of the University of California Riverside Institute for Integrative Genome Biology. DNA sequences were edited using Sequencher (version 4.1.2, Gene Codes Corp., Ann Arbor, MI) and aligned using Clustal W (version 1.83, European Bioinformatics Institute, Cambridge, UK). DNA sequences were translated into amino acid sequences using the computer program ExPASy Translate Tool. Amino acid sequences were compared to the corresponding OS-1 regions of M. fructicola (i.e., Mfos 1p), Botryotinia fuckeliana (i.e., BOS-1), A. alternata (i.e., AaHK1p), and $N$. crassa (i.e., OS-1p) with GenBank Accession numbers DQ517299, AAL30826, AAO49475, and AAB01979, respectively.

Immuno-detection of OS-2 related MAP kinases of $\boldsymbol{P}$. digitatum. Two $P$. digitatum isolates sensitive to fludioxonil ( $\mathrm{Pd}$ and 2152), as well as one MR isolate (12MR) and one HR isolate (13HR) were grown in $8 \mathrm{ml} \mathrm{PDB}$ in 6-cm petri dishes for 5 days at $25^{\circ} \mathrm{C}$ after inoculation with $100 \mu$ of a conidial suspension $(1 \times$ $10^{6}$ conidia/ml). Technical grade fludioxonil dissolved in DMSO was then added to the cultures to final concentrations of 1 and $100 \mu \mathrm{g} / \mathrm{ml}$. Control plates only received the equivalent amount of DMSO. After 10 min of exposure, protein extracts were obtained using procedures described in Jones et al. (25). For this, mycelial mats were ground in liquid nitrogen using a mortar and pestle and the homogenate was transferred to 2-ml screw-top microcentrifuge tubes containing $1 \mathrm{ml}$ of chilled $3 \mathrm{mM}$ phenylmethylsulfonyl fluoride (Sigma-Aldrich) in $95 \%$ ethanol and $0.2 \mathrm{~g}$ of glass beads $(0.5 \mathrm{~mm}$ in diameter). The tubes were vortexed three times for $60 \mathrm{~s}$ each. Between vortexing, samples were placed on ice for $60 \mathrm{~s}$. Extracts were stored at $-20^{\circ} \mathrm{C}$ for at least $16 \mathrm{~h}$. Samples were then centrifuged at $16,000 \times g$ for $10 \mathrm{~min}$ at $4^{\circ} \mathrm{C}$. The supernatant was removed and precipitated proteins were dried on the beads for $30 \mathrm{~min}$ in a vacuum concentrator (Eppendorf, Westbury, NY). Samples were re-suspended in $250 \mu \mathrm{l}$ of $1 \%$ sodium dodecyl sulfate (SDS) by heating at $85^{\circ} \mathrm{C}$ for $5 \mathrm{~min}$. After centrifugation for $5 \mathrm{~min}$ at $16,000 \times g$ at $25^{\circ} \mathrm{C}$, the protein supernatant was removed. This sample reconstitution was repeated once. Supernatants were combined, heated again for $5 \mathrm{~min}$ at $85^{\circ} \mathrm{C}$ and centrifuged to remove residual cellular debris. The concentration of total proteins was determined using the bicinchoninic acid protein assay (Pierce Chemical, Rockford, IL) and extract aliquots containing $50 \mu \mathrm{g}$ of protein were subjected to SDS-polyacrylamide gel electrophoresis as described previously (33). OS-2 related MAP kinases were detected using western blot analysis. A commercially available antibody (anti-p38 No. 9211; 1:1000 dilution; Cell Signaling Technology, Inc., Beverly,
MA) was used to detect phosphorylated OS-2, whereas AntiHog1p antibody (No. sc-9079; 1:600 dilution; Santa Cruz Biotechnology, Inc., Santa Cruz, CA) was used to detect all forms of the OS-2 protein. Incubation with secondary antibody and chemiluminescent detection were performed as described previously (33).

Determination of glycerol concentration in mycelium of $P$. digitatum and $N$. crassa. Determination of glycerol concentration was done following a modified protocol of Fujimura et al. (14). $P$. digitatum isolates $\mathrm{Pd}, 12 \mathrm{MR}$, and $13 \mathrm{HR}$ were grown in 6 -cm petri dishes with $8 \mathrm{ml}$ of PDB for 5 days at $25^{\circ} \mathrm{C}$ on a rotary shaker at $80 \mathrm{rpm}$. Plates were inoculated with $100 \mu \mathrm{l}$ of a conidial suspension $\left(1 \times 10^{6}\right.$ conidia/ml $)$. Isolates of $N$. crassa were grown in 100-ml Erlenmeyer flasks with $20 \mathrm{ml}$ of Vogel's medium for $24 \mathrm{~h}$ at $25^{\circ} \mathrm{C}$ on a rotary shaker at $180 \mathrm{rpm}$. Flasks were inoculated with $1 \mathrm{ml}$ of a conidial suspension $\left(1 \times 10^{7}\right.$ conidia/ml $)$. For each fungal isolate, an additional set of cultures was prepared for the determination of dry weight. After incubation in $10 \mu \mathrm{g}$ of fludioxonil/ml for $4 \mathrm{~h}$, the mycelia were collected by filtration through filter paper (No. 1; Whatman International Ltd., UK), washed with sterile distilled water, homogenized in $5 \mathrm{ml}$ sterile distilled water using a polytron tissue grinder (PowerGen 700; Fisher Scientific, Pittsburgh, PA), and incubated at $80^{\circ} \mathrm{C}$ for $5 \mathrm{~min}$. After centrifugation at 4,000 $\times g$, the glycerol concentration in the supernatant was measured spectrophotometrically at $340 \mathrm{~nm}$ using a UV-glycerol assay (Boehringer Mannheim $\mathrm{GmbH}$, Germany). Glycerol concentrations were based on mycelium dry weight for each isolate.

Effect of amino acids and homocysteine on inhibition of $P$. digitatum and $B$. cinerea by the anilinopyrimidine fungicides cyprodinil and pyrimethanil. $\mathrm{EC}_{50}$ values for mycelial growth of isolates of $P$. digitatum $(\mathrm{Pd})$ and $B$. cinerea $(\mathrm{Bc})$ for pyrimethanil and cyprodinil were determined using the SGD method as described above. Stock concentrations of cyprodinil and pyrimethanil (50 and $100 \mu \mathrm{g} / \mathrm{ml}$, respectively) were spirally applied to $15-\mathrm{cm}$ petri dishes containing a synthetic medium that has been suggested for the use of anilinopyrimidines (AP) fungicides by the AP working group of the Fungicide Resistance Action Committee (FRAC). This medium contained $10 \mathrm{~g}$ of glucose, $1.5 \mathrm{~g}$ of $\mathrm{K}_{2} \mathrm{HPO}_{4}, 2 \mathrm{~g}$ of $\mathrm{KH}_{2} \mathrm{PO}_{4}, 1 \mathrm{~g}$ of $\left(\mathrm{NH}_{4}\right)_{2} \mathrm{SO}_{4}, 0.5 \mathrm{~g}$ of $\mathrm{MgSO}_{4} 7 \mathrm{H}_{2} \mathrm{O}$, and $12.5 \mathrm{~g}$ of agar per liter of distilled water $(20,36)$. The medium was used without or with the addition of the following amino acids (100 $\mu \mathrm{M}$ each): L-alanine, L-arginine, Lasparagine, L-cysteine, L-cystine, L-glutamine, L-glycine, Lhistidine, L-isoleucine, L-leucine, L-lysine, L-methionine, Lphenylalanine, L-proline, L-serine, L-threonine, L-tryptophan, Ltyrosine, and L-valine (Sigma-Aldrich). All of these amino acids were used in a mixture; whereas L-methionine, L-cysteine, and Lcystine were also used individually. In an additional treatment, the AP medium was also amended with DL-homocysteine (SigmaAldrich) at $1,000 \mu \mathrm{M}$. $\mathrm{EC}_{50}$ values were determined after 5 days of incubation at $25^{\circ} \mathrm{C}$. $\mathrm{EC}_{50}$ factors were calculated as the ratio of $\mathrm{EC}_{50}$ values in the presence of amino acids or precursors as compared to $\mathrm{EC}_{50}$ values on nonamended $\mathrm{AP}$ medium. The $\mathrm{EC}_{50}$ factor for the fungi grown on AP medium was assigned the value of 1 . This experiment was conducted three times.

Statistical analysis of data. Percentage data were arcsine transformed. Growth and $\mathrm{EC}_{50}$ values were $\log _{10}$-transformed. Bartlett's test for homogeneity of variances was performed for repeated experiments and data sets with homogeneous variances $(P<0.05)$ were combined for further analysis using one- or two-way classification of data depending on the experiment. In experiments with multiple comparisons, a balanced factorial design was used for comparing treatments. For error control, all treatments were in a randomized-complete-blocks design. Values were analyzed using general linear model or analysis of variance and least significant difference mean separation procedures of SAS version 9.1 (SAS Institute, Cary, NC). 


\section{RESULTS}

Fungal growth, sporulation, and sensitivity of isolates of $P$. digitatum to fludioxonil, iprodione, and osmotic stress. In comparisons of fungal growth among isolates of $P$. digitatum studied, the two isolates sensitive to fludioxonil (i.e., isolates Pd and 2152) had significantly higher growth rates than isolates that were less sensitive to this fungicide (Table 1). In addition, sporulation was also reduced in the latter isolates. Sporulation was lowest for isolates with the highest resistance to fludioxonil even after extended incubation. $\mathrm{EC}_{50}$ values of fludioxonil for the two sensitive isolates were 0.02 and $0.04 \mu \mathrm{g} / \mathrm{ml}$, respectively (Table 1). $\mathrm{EC}_{50}$ values of isolates with reduced sensitivity to fludioxonil were significantly $(P<0.01)$ higher than those of sensitive isolates ( $\mathrm{Pd}$ and 2152). Less sensitive isolates were grouped into two categories: values for moderately resistant (MR) isolates (i.e., $2 \mathrm{MR}, 7 \mathrm{MR}$, and $12 \mathrm{MR}$ ) ranged from 0.08 to $0.65 \mu \mathrm{g} / \mathrm{ml}$, whereas values for highly resistant (HR) isolates (i.e., $1 \mathrm{HR}, 13 \mathrm{HR}$, and 15HR) were $>40 \mu \mathrm{g} / \mathrm{ml}$ (Table 1 ).

Sensitivities to fludioxonil among isolates were also compared by measuring growth on agar media amended with 0.1 or $10 \mu \mathrm{g}$ of fludioxonil/ml. The two sensitive isolates did not grow at either concentration of fludioxonil (Table 1). Growth of the three MR isolates on agar amended with $0.1 \mu \mathrm{g}$ of fludioxonil $/ \mathrm{ml}$ was between 75.3 and $104.4 \%$ as compared to nonamended agar, whereas on agar amended with $10 \mu \mathrm{g}$ of fludioxonil $/ \mathrm{ml}$, no growth occurred. Growth of two of the three HR isolates of $P$. digitatum was not inhibited by $10 \mu \mathrm{g}$ of fludioxonil $/ \mathrm{ml}$, whereas growth of the third isolate was inhibited with percent radial growth $58.9 \%$ as compared to growth on nonamended agar.

The two fludioxonil-sensitive isolates were also significantly $(P<0.01)$ more sensitive to iprodione than the MR and HR isolates (Table 1). Thus, growth of isolates $\mathrm{Pd}$ and 2152 on agar amended with $1 \mu \mathrm{g}$ of iprodione/ml was 35.5 and $53.9 \%$, respectively, of the nonamended control and no growth was observed at a concentration of $25 \mu \mathrm{g} / \mathrm{ml}$. None of the MR and HR isolates was inhibited in growth by $1 \mu \mathrm{g}$ of iprodione/ml, whereas on agar amended with $25 \mu \mathrm{g}$ of iprodione/ml, inhibition was $\leq 27.1 \%$. Thus, no consistent relationship was found between the HR and MR fludioxonil-resistant isolates to this concentration of iprodione.

In osmotic stress studies, isolates were grown on agar media amended with 10 or $40 \mathrm{~g}$ of $\mathrm{NaCl} /$ liter. Although there were significant $(P<0.01)$ differences in inhibition among isolates, there was no correlation between osmotic stress tolerance and fludioxonil sensitivity (Table 1). In addition, isolates responded to osmotic stress with a quite narrow range of inhibition. Thus, radial growth among all isolates at $10 \mathrm{~g}$ of $\mathrm{NaCl} /$ liter as compared to the nonamended control ranged between 24.5 and $46.7 \%$. At 40 $\mathrm{g}$ of $\mathrm{NaCl} /$ liter growth ranged between 3.5 and $14.4 \%$.

Sequence analysis of the $\mathrm{N}$-terminal amino acid repeat region of Pdos-1 from isolates of $\boldsymbol{P}$. digitatum. Using primers PdHKF and PdHKR and $P$. digitatum DNAs as templates, amplified DNA fragments were approximately $1.6 \mathrm{~kb}$ in size. Sequences were translated to a frame of 561 amino acids, which showed high homology to open reading frames of published twocomponent HK genes from other fungi (Fig. 1). The partial length amino acid sequence from $P$. digitatum included a six-repeat domain motif of approximately 90 amino acids each and a kinase domain with the autophosphorylation site, known also as H-box. Based on sequence alignments, no introns were present in the $P$. digitatum $\mathrm{HK}$ gene region investigated. Comparisons of DNA products from two fludioxonil-sensitive, three fludioxonil MR, and three fludioxonil HR isolates revealed a base substitution from aspartate aminotransferase to ACT at codon 314 within the fourth repeat domain in the sensitive isolate 2152, resulting in an amino acid change from isoleucine to leucine. Another amino acid substitution was found for two of the three fludioxonil HR isolates (i.e., 13HR and 15HR) in the fifth repeat, where glycine at codon 392 was substituted for glutamic acid that was found in all remaining isolates studied. The consensus sequence of the Pdos- 1 gene had 79.1, 83.9, 83.6, and $82.9 \%$ amino acid identity to the corresponding regions of fludioxonil-sensitive isolates of $A$. alternata, B. cinerea, M. fructicola, and N. crassa, respectively.

Immuno-detection of OS-2 related MAP kinases of $P$. digitatum. To investigate whether the activation of PdOS-2 is induced by fludioxonil, we determined the levels of PdOS-2 and phosphorylated PdOS-2 in fludioxonil-sensitive and -resistant isolates of $P$. digitatum. Based on Western analysis, similar levels (as observed by relative band intensity) of PdOS-2 protein were detected in the isolates investigated when equivalent amounts of total protein were assayed, and the molecular mass of the detected protein with $43 \mathrm{kD}$ was similar to that reported for the OS-2 protein of $N$. crassa (Fig. 2). Differences, however, were detected in levels of phosphorylated PdOS-2 protein between fludioxonilsensitive and -resistant isolates, both without and following exposure to fludioxonil. In nonexposed mycelia, the amount of phosphorylated PdOS-2 was higher (i.e., band intensity) in the two fludioxonil-sensitive isolates compared with the MR and HR isolates. The lowest amount was present in the HR isolate. An increase in phosphorylated PdOS-2 was observed for all four

TABLE 1. Fungal growth rates, sporulation, and fungicide and osmotic stress sensitivity of Penicillium digitatum field isolates

\begin{tabular}{|c|c|c|c|c|c|c|c|c|c|c|c|c|c|c|c|c|c|}
\hline \multirow[b]{4}{*}{ Isolates $^{\mathrm{a}}$} & & & \multirow{4}{*}{$\begin{array}{l}\text { Sporulation }^{\mathrm{c}} \\
\text { (rating) }\end{array}$} & \multirow{4}{*}{$\begin{array}{c}\mathrm{EC}_{50} \text { values } \\
\text { fludioxonil } \\
(\mu \mathrm{g} / \mathrm{ml})^{\mathrm{d}}\end{array}$} & \multirow[b]{4}{*}{ LSD } & \multicolumn{12}{|c|}{ Radial growth $(\%)^{\mathrm{e}}$} \\
\hline & & & & & & \multicolumn{4}{|c|}{ Fludioxonil ( $\mu \mathrm{g} / \mathrm{ml})$} & \multicolumn{4}{|c|}{ Iprodione $(\mu \mathrm{g} / \mathrm{ml})$} & \multicolumn{4}{|c|}{$\mathrm{NaCl}$ (g/liter) } \\
\hline & \multicolumn{2}{|c|}{ Growth rate ${ }^{\mathrm{b}}$} & & & & \multicolumn{2}{|c|}{0.1} & \multicolumn{2}{|c|}{10} & \multicolumn{2}{|c|}{1} & \multicolumn{2}{|c|}{25} & \multicolumn{2}{|c|}{10} & \multicolumn{2}{|c|}{40} \\
\hline & $\overline{(\mathrm{mm} / \text { day })}$ & $\overline{\operatorname{LSD}^{\mathrm{f}}}$ & & & & $\%$ & LSD & $\%$ & LSD & $\%$ & LSD & $\%$ & LSD & $\%$ & $\overline{\text { LSD }}$ & $\%$ & LSD \\
\hline $\mathrm{Pd}$ & 8.2 & A & +++ & 0.02 & $\mathrm{~F}$ & 0 & $\mathrm{E}$ & 0 & $\mathrm{C}$ & 35.5 & $\mathrm{D}$ & 0 & $\mathrm{C}$ & 40.6 & $\mathrm{AB}$ & 6.1 & B \\
\hline 2152 & 7.2 & A & +++ & 0.04 & E & 0 & E & 0 & $\mathrm{C}$ & 53.9 & $\mathrm{C}$ & 0 & $\mathrm{C}$ & 44.4 & $\mathrm{AB}$ & 14.3 & A \\
\hline $2 \mathrm{MR}$ & 5.5 & B & ++ & 0.65 & B & 105.5 & C & 0 & $\mathrm{C}$ & 112.9 & A & 105.3 & A & 33.9 & $\mathrm{C}$ & 14.4 & A \\
\hline $7 \mathrm{MR}$ & 5.8 & B & ++ & 0.08 & $\mathrm{D}$ & 70.1 & $\mathrm{D}$ & 0 & $\mathrm{C}$ & 104.3 & $\mathrm{AB}$ & 72.9 & B & 46.7 & A & 13.3 & A \\
\hline $12 \mathrm{MR}$ & 5.6 & B & ++ & 0.13 & $\mathrm{C}$ & 77.1 & $\mathrm{D}$ & 0 & $\mathrm{C}$ & 107.6 & $\mathrm{AB}$ & 73.3 & B & 47 & A & 12.8 & A \\
\hline $1 \mathrm{HR}$ & 5.1 & $\mathrm{BC}$ & + & $>40^{\mathrm{g}}$ & A & 113.5 & B & 129.6 & A & 107.7 & $\mathrm{AB}$ & 80.4 & B & 38.9 & $\mathrm{BC}$ & 11.9 & A \\
\hline 13HR & 5.7 & B & + & $>40$ & A & 99.4 & $\mathrm{C}$ & 58.9 & B & 99.9 & B & 95.9 & A & 24.5 & $\mathrm{D}$ & 3.5 & B \\
\hline $15 \mathrm{HR}$ & 4.4 & $\mathrm{C}$ & + & $>40$ & A & 124.4 & A & 127.4 & A & 114 & A & 101.7 & A & 41.9 & $\mathrm{AB}$ & 10.8 & A \\
\hline
\end{tabular}

a Sensitivity of $P$. digitatum isolates to fludioxonil: Pd and 2152 - sensitive; $2 \mathrm{MR}, 7 \mathrm{MR}$, and 12MR - moderately resistant; $1 \mathrm{HR}, 13 \mathrm{HR}$, and $15 \mathrm{HR}$ - highly resistant.

${ }^{b}$ Fungal growth rate was determined on potato dextrose agar plates that were inoculated and incubated for 5 days at $25^{\circ} \mathrm{C}$.

c Sporulation rating was determined as low $(+)$, medium $(++)$, or high $(+++)$.

${ }^{\mathrm{d}} \mathrm{EC}_{50}$ values were determined using the spiral gradient dilution method.

e Colony radial growth on amended plates was expressed as percentage of radial growth on nonamended plates.

${ }^{f}$ Means followed by the same letter within a column are not significantly different $(P>0.05)$ following an analysis of variance and least significant difference (LSD) mean separation procedure.

g $\mathrm{EC}_{50}$ values could not be determined because isolates were highly resistant. 
isolates evaluated after mycelia were exposed to fludioxonil for $10 \mathrm{~min}$ immediately before sampling. Similar amounts of protein were observed for the two rates of fludioxonil (i.e., 1 and $100 \mu \mathrm{g} / \mathrm{ml}$ ) for the two sensitive isolates and the MR isolate (Fig.
2). For the $\mathrm{HR}$ isolate, $100 \mu \mathrm{g}$ of fludioxonil $/ \mathrm{ml}$ increased phosphorylated PdOS-2 to higher levels than $1 \mu \mathrm{g} / \mathrm{ml}$. Overall, the highest levels of phospho-PdOS-2 were detected in the sensitive isolates.

\begin{abstract}
Mfos1 ERVAALERELKKHQQANEAFQKALREIGEIVTAVARGDLSKKVQIHSVEMDPEITTFKRVINTMMDQLQIFSSEV 254 Bos1 ERVAALERELKKHQQANEAFQKALREIGEIVTAVARGDLSKKVQIHSVEMDPEITTFKRVINTMMDQLQIFSSEV 257 AaHK1 Os1

Pdos 1 ERVATLERELWKHQKANEAFQKALRE IGEIVTAVARGDLSKKVRMNSVEMDPE ITTFKRTINTMMDQLQVFSSEV 235 -----------NEAFQKALREIGGI ITQVANGDLSMKVQIHPLEMDPEIATFKRTINTMMDQLQVFGSEV 59

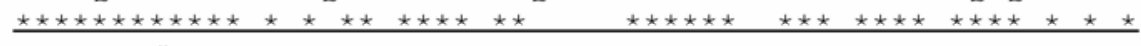
Repeat \#1

Mfos1 SRVAREVGTEGILGGQAKISGVDGT WKELTDNVNVMAQNLTDQVREIASVTTAVAHGDLTQKIERPAQGEILQL 328 Bos 1

AaHK1

Os 1

Pdos 1 SRVAREVGTEGILGGQAKISGVDGT WKELTDNVNVMAQNLTDQVREIASVTTAVAHGDLTQKIERPAQGEILQL 331 TFLAREVGTEGRLGGQANLPGVAGI WAELTDSVNGMAKNLTDQVREIAVVTTAVAMGDLSRKIERPARGEILQL 135 SRVAREVGTEGILGGQAQIEGVDGT WKELTDNVNVMAQNLTDQVREIASVTTAVAHGDLTKKIERPAKGEILQL 309 SRVAREVGTEGILGGQAQITGVHGI WKELTENVNIMAKNLTDQVREIAAVTTAVAHGDLSQKIESRAQGEILEL 133

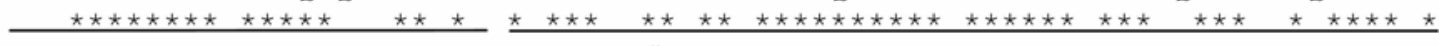
Repeat \#2
\end{abstract}

Mfos1 QQTINTMVDQLRTFAAEVTRVARDVGTEGILGGQAEIEGVQGM WNTLIVNVNAMANNLTTQVRDIAIVTTAVAK 402 Bos 1

AaHK1

Os 1

Pdos 1 QQTINTMVDQLRTFAAEVTRVARDVGTEGILGGQAEIEGVQGM WNTLIVNVNAMANNLTTQVRDIAIVTTAVAK 405 QQT INSMVDQLQSFATQVTKVARDVGTEGKLGGQAE IAGVKGM WNELTVNVNAMAQNLTTQVRDIAQVTTAVAQ 209 QQTINTMVDQLRTFASEVTRVARDVGTEGILGGQADVEGVQGM WNELTVNVNAMANNLTTQVRDIIKVTTAVAK 383 QQTINTMVDQLRTFATEVTRVARDVGTEGVLGGQAQIEGVQGM WNELTVNVNAMANNLTTQVRDIATVTKAVAK 207

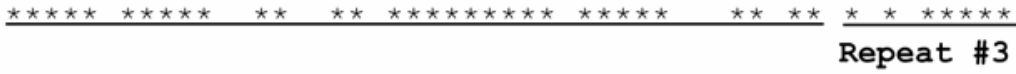

Mfos GDLTQKVQAECKGEIKQLKETINSMVDQLQQFAREVTKIAREVGTEGRLGGQATVHDVEGT WRDLTENVNGMAM 476 Bos1

AaHK1 Os 1

Pdos 1 GDLTQKVQAECKGEIKQLKETINSMVDQLQQFAREVTKIAREVGTEGRLGGQATVHDVEGT WRDLTENVNGMAM 479 GNLTRKVEAECKGEILELKNT INRMVDQLQQFAHEVTKIAREVGSEGRLGGQATVHGVEGT WKDLTENVNGMAM 283 GDLTQKVQAECRGEIFELKKTINSMVDQLQQFAREVTKIAREVGTEGRLGGQATVHDVQGT WRDLTENVNGMAM 457 GDLTQKVQANCKGEIAELKNI INSMVDQLRQFAQEVTKIAKEVGTDGVLGGQATVNDVEGT WKDLTENVNRMAN 281

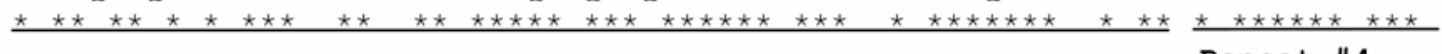

Repeat \#4

Mfos1 NLTTQVREIAKVTTAVARGDLTKKIEVEVQGEIASLKDTINTMVDRLGTFAFEVSKVAREVGTDGTLGGQAQVDN 551 Bos 1 AaHK

Os 1

Pdos 1 NLTTQVREIAKVTTAVARGDLTKKIEVEVQGEIASLKDTINTMVDRLSTFAFEVSKVAREVGTDGTLGGQAQVDN 554 NLTTQVRE IAEVTTAVARGDLSRKVKAEVQGEILSLKITINTMVDRLNTFAQEVSKVAREVGTDGILGGQAQVDN 358 NLTTQVREIAKVTTAVAKGDLTKKIGVEVQGEILDLKNT INTMVDRLGTFAFEVSKVAREVGTDGTLGGQAQVDN 532 NLTTQVRE IADVTTAVAKGDLTKKVTANVQGEILDLKST INGMVDRLNTFAFEVSKVAREVGTDGTLGGQAKVDN 356

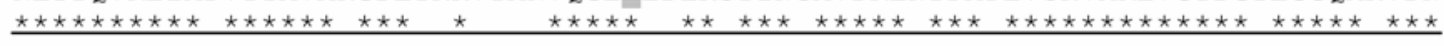

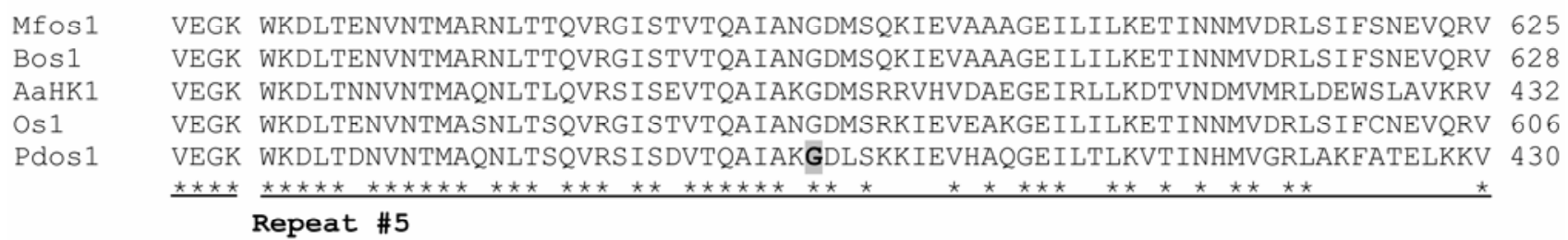

Mfos1 AKDVGVDGKMGGQADVAGIGGR WKEITTDVNTMANNLTTQVRAFGDITNAATDGDFTKLITVEASGEMDELKRK 699 Bos1 AKDVGVDGKMGGQADVAGIGGR WKEITTDVNTMANNLTTQVRAFGDITNAATDGDFTKLITVEASGEMDELKRK 702 AaHK1 ARDVGVDGKMGGQADVRDIDGR WKEITTDVNTMAQNLTSQVRAFGDITNAAMEGKFTQ-ITVEASGEMDELKRK 505 Os1 AKDVGVDGIMGGQADVAGLKGR WKEITTDVNTMANNLTAQVRAFGDITNAATDGDFTKLVEVEASGEMDELKKK 680 Pdos1 ARDVGVDGKMGGQANVEGIAGT WKEITEDVNTMAENLTSQVRAFGEITDAATDGDFTKLITVNASGEMDELKRK 504

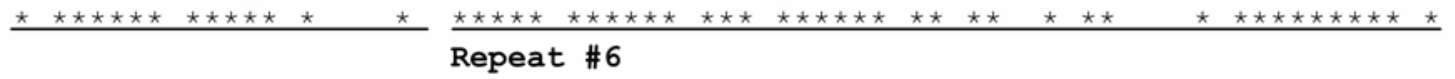

Mfos1 INQMVYNLRDSIQRNTLAREAAEFANRT KSEFLANMSHEIRTPMNGIIGMTQLTLDT 756

BOS1 INQMVYNLRDSIQRNTLAREAAEFANRT KSEFLANMSHEIRTPMNGIIGMTQLTLDT 759

AaHK1 INQMVSSLRESIQRNTAAREAAELANKT KSEFLANMSHEIRTPMNGIIGMTQLTLDT 562

Os1 INQMVYNLRDSIQRNTQAREAAELANKT KSEFLANMSHEIRTPMNGIIGMTQLTLDT 737

Pdos1 INKMVSNLRDSIQRNTAAREAAELANRT KSEFLANMSHEIRTPMNGIIGMTQLTLDT 561

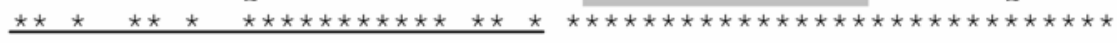

Fig. 1. Comparison of the predicted amino acid sequence of the partial Pdos- 1 gene of Penicillium digitatum with the corresponding regions of Monilinia fructicola (Mfos1), Botryotinia fuckeliana (Bos1), Alternaria alternata (AaHK1), and Neurospora crassa (os-1). Amino acid identities are indicated by an asterisk. Gaps introduced for the alignment are indicated by hyphens. The six predicted 90 -amino acid repeat units are underlined. The conserved $\mathrm{H}$ box is shaded. The bold shaded amino acids at codons 314 and 392 indicate sites where amino acid changes were found among some isolates of $P$. digitatum. GenBank Accession Numbers: DQ517299 (Mfos1), AAL30826 (Bos1), AAO49475 (AaHK1), and AAB01979 (os-1). 
Determination of glycerol accumulation in mycelium of $P$. digitatum and $N$. crassa. Glycerol contents in mycelia of fludioxonil-sensitive and -resistant isolates of $P$. digitatum were compared to those of wild type and $o s-2$ mutant isolates of $N$. crassa, both without and following a 4-h exposure to $10 \mu \mathrm{g}$ of fludioxonil $/ \mathrm{ml}$. These studies resulted in a highly significant model and differences $(P<0.01)$ between fungal isolates and nontreated and fludioxonil-treated mycelia. In addition, there was a highly significant interaction $(P<0.01)$ between treatment and fungal isolates, indicating that isolates performed differently in the presence of fludioxonil. Thus, data in Figure 3 are presented separately for each fungal isolate.

For $N$. crassa, glycerol content in unexposed mycelia was $7.7 \mu \mathrm{g} / \mathrm{mg}$ of mycelium dry weight for the os-2 mutant and $9.8 \mu \mathrm{g} / \mathrm{mg}$ dry weight for the wild-type isolate. After exposure to $10 \mu \mathrm{g}$ of fludioxonil/ml, there was a significant increase in glycerol concentration in the wild type isolate $(20 \mu \mathrm{g} / \mathrm{mg}$ dry weight), but not in the os-2 mutant $(7.4 \mu \mathrm{g} / \mathrm{mg}$ dry weight) (Fig. 3A).

For $P$. digitatum, glycerol content in the untreated controls of the fludioxonil-sensitive isolate $\mathrm{Pd}$, and the MR and HR isolates were $8.6,1.9$, and $1.3 \mu \mathrm{g} / \mathrm{mg}$ of dry weight, respectively (Fig. 3B). After exposure to fludioxonil, concentrations significantly increased in the sensitive and MR isolates, but not in the HR isolate. Concentrations in isolates $\mathrm{Pd}, \mathrm{MR}$, and $\mathrm{HR}$ were 18, 6.4, and $1.7 \mu \mathrm{g} / \mathrm{mg}$ of mycelium dry weight, respectively.

Effect of amino acids and homocysteine on inhibition of $P$. digitatum and $B$. cinerea by the AP fungicides cyprodinil and pyrimethanil. $\mathrm{EC}_{50}$ values for mycelial growth of $B$. cinerea and $P$. digitatum were determined for cyprodinil and pyrimethanil using AP culture medium without and with the addition of selected amino acids or homocysteine, a precursor in the methionine biosynthetic pathway (Table 2). Calculated $\mathrm{EC}_{50}$ factors $\left(\mathrm{EC}_{50}\right.$ value in the presence of amino acid(s) or precursor/EC $\mathrm{C}_{50}$ value without amino acid(s) or precursor) for each additive were compared for each fungus and each of the two AP fungicides.

In $\mathrm{EC}_{50}$ value and $\mathrm{EC}_{50}$ factor comparisons for $\mathrm{B}$. cinerea, amino $\operatorname{acid}(\mathrm{s}) /$ precursor, fungicide, and their interaction were highly significant $(P<0.01)$. Because the interaction between fungicide and additive was significant, data for $\mathrm{EC}_{50}$ values and factors were analyzed for each fungicide. The addition of the 19 amino acids, the three individual sulfur-containing amino acids, and DL-homocysteine resulted in significantly different $\mathrm{EC}_{50}$ values and $\mathrm{EC}_{50}$ factors (Table 2). $\mathrm{EC}_{50}$ factors were all higher for pyrimethanil than for cyprodinil for all tested amino acids/precursors. $\mathrm{EC}_{50}$ factors for both fungicides were highest when all 19 amino acids were added with values of 3.21 and 7.68 for cyprodonil and pyrimethanil, respectively. Thus, the addition of the amino acids resulted in increased $\mathrm{EC}_{50}$ values compared with the nonamended medium and reduced toxicity of the two AP fungicides evaluated. The addition of the three sulfur-containing amino acids or DL-homocysteine resulted in lower $\mathrm{EC}_{50}$ factors than when all 19 amino acids were added and they ranged from 1.33 to 1.63 for cyprodinil and from 2.36 to 3.26 for pyrimethanil. This indicates that these additives were less effective in reducing the toxicity of the fungicides.

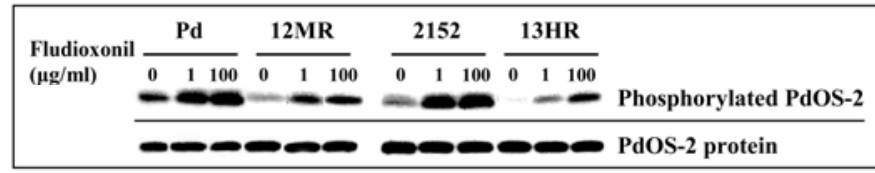

Fig. 2. Immuno-detection of Pdos-2 in extracts from isolates of Penicillium digitatum. Fludioxonil-sensitive (Pd and 2152), moderately resistant (12MR) and highly-resistant (13HR) isolates were grown for 5 days in potato dextrose broth. Cultures were treated with 0,10 , or $100 \mu \mathrm{g}$ fludioxonil $/ \mathrm{ml}$ for the last $10 \mathrm{~min}$ of incubation. Phosphorylated OS-2 protein approximately $43 \mathrm{kD}$ in size was detected in Western analysis with anti-p38, whereas, an anti-Hog1p antibody was used for detection of all forms of the OS-2 protein.
Similar $\mathrm{EC}_{50}$ value and $\mathrm{EC}_{50}$ factor comparisons were made for $P$. digitatum. Amino acid, fungicide, and their interaction were highly significant $(P<0.01)$ for $\mathrm{EC}_{50}$ values. For $\mathrm{EC}_{50}$ factors, amino acid, and the interaction of amino acid and fungicide were highly significant $(P<0.01)$ but the fungicides were not significant $(P \geq 0.45)$. Because the interaction between fungicide and additive was significant for both independent variables, data for $\mathrm{EC}_{50}$ values and factors were analyzed for each fungicide. For cyprodinil, the addition of all 19 amino acids resulted in the highest $\mathrm{EC}_{50}$ values and factors (i.e., 1.42) compared with the other additives and the AP medium (Table 2). For pyrimethanil, the addition of all 19 amino acids and L-cysteine to the AP medium also resulted in a significant increase of the $\mathrm{EC}_{50}$ factor to a value of 1.11 and 1.14 , respectively. Thus, the addition of certain amino acids resulted in a reduced toxicity of the two AP fungicides. In comparisons of the two fungi for each fungicide, the effect of each additive was significantly less for $P$. digitatum than for B. cinerea.

\section{DISCUSSION}

Fludioxonil and pyrimethanil represent two classes of fungicides that in the last 10 years have been registered on a wide variety of crops and that are now being introduced for postharvest use on citrus. The citrus pathogen $P$. digitatum has a high potential to develop resistance to fungicides due to its abundant spore production, repeated postharvest fungicide applications to the same lot of fruit, and because fruit are harvested and processed year-round in California without a break in the postharvest disease cycle. Resistant populations of the fungus that were associated with crop losses have been found for all citrus postharvest fungicides previously registered in the United States. Thus, resistance management strategies are critical for maintaining fungicide efficacy. In addition, knowledge on the modes of action and subsequent resistance mechanisms in the target fungus and comparisons with other fungal species may allow for novel approaches in preventing the selection of resistant populations.

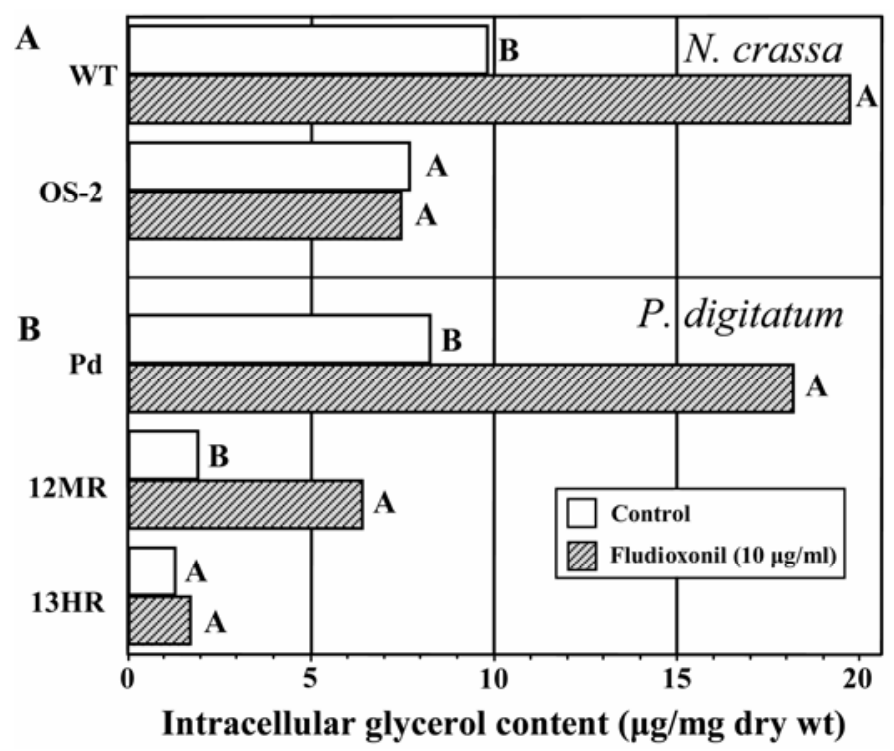

Fig. 3. Effect of fludioxonil on concentrations of intracellular glycerol in isolates of Neurospora crassa and Penicillium digitatum. A, Amount of glycerol in wild-type (Nc) and $o s-2$ mutant (OS-2:UCLA80) strains of $N$. crassa. Cultures were grown in Vogel's medium for $24 \mathrm{~h}$ and fludioxonil was added to a final concentration of $10 \mu \mathrm{g} / \mathrm{ml}$ for the last $4 \mathrm{~h}$ of incubation. B, Amount of glycerol in fludioxonil-sensitive (Pd), fludioxonil moderately resistant (12MR), and highly resistant (13HR) isolates of $P$. digitatum. Cultures were grown for 5 days in potato dextrose broth and treated with fludioxonil as for $N$. crassa. Glycerol contents are expressed in $\mu \mathrm{g}$ of glycerol per milligram of mycelium dry weight. Treatments were statistically compared pairwise for each isolate. 
Because phenylpyrrole-resistant isolates of a variety of fungi have been found to be more sensitive to osmotic stress, the intent of the present study was to elucidate if selected characteristics of osmotic stress regulation that have been described are also found in naturally-occurring fludioxonil-resistant isolates of the citrus pathogen $P$. digitatum. These characteristics include sensitivity to dicarboximide fungicides and high osmotic conditions, mutations in an HK gene related to $o s-1$, as well as differences in OS-2 related MAP kinase activity and glycerol accumulation.

Although the dicarboximide fungicide iprodione is not highly effective against $P$. digitatum, we found a relationship between phenylpyrrole- and dicarboximide-sensitivity for the isolates evaluated as in most previous studies with other fungi. This relationship, however, was not absolute. For example, $P$. digitatum isolates sensitive to fludioxonil were also found to be more sensitive to iprodione as compared to isolates with reduced sensitivity to fludioxonil. Among the latter isolates, however, there was no consistent difference in inhibition by iprodione between moderately and highly fludioxonil-resistant isolates. The fact that the two fludioxonil-resistant types of $P$. digitatum isolates could not be differentiated based on their sensitivity against iprodione indicates that in this organism, mechanisms of action for the two classes of fungicides are not identical.

This conclusion is also supported by genetic studies with $B$. cinerea where resistance to dicarboximides and phenylpyrroles segregated independently, suggesting that different genes regulate resistance to these two classes of fungicides (49). In addition, iprodione resistance, but not fludioxonil resistance, in field isolates of this fungus was shown to correlate with enhanced production of catalase (48). Also, in studies with $N$. crassa an intracellular calcium- and cAMP-independent protein kinase was inhibited by phenylpyrrole but not by dicarboximide fungicides (46). These observations, together with our findings in $P$. digitatum suggest that the mode of action of dicarboximide and phenylpyrrole fungicides is not identical, but that different target sites may be involved within related biochemical pathways that in some fungal systems have an affinity to both fungicide classes.

In subsequent studies, we determined the effect of osmotic stress on growth of fludioxonil-sensitive and -resistant isolates of $P$. digitatum. Although significant differences were found among isolates, there was no correlation between osmotic stress tolerance and the degree of fludioxonil-sensitivity among sensitive, MR, and HR isolates. In addition, inhibitory effects of the osmoticum sodium chloride on growth of $P$. digitatum were within a rather narrow range (i.e., 24.5 to $46.7 \%$ inhibition in growth for $10 \mathrm{~g}$ of $\mathrm{NaCl} /$ liter and 3.5 to $14.4 \%$ inhibition for $40 \mathrm{~g}$ of $\mathrm{NaCl} / \mathrm{liter}$ ). Thus, there was no relationship between sensitivity to osmotic stress and sensitivity to fludioxonil. This contrasts with several studies that have been conducted with other fungi where dicarboximide-resistant laboratory mutants and field isolates with a reduced sensitivity to phenylpyrroles showed an increased sensitivity to osmotic stress $(6,14,45,52)$. Still, other studies indicated no close correlation between sensitivity to osmotic stress and sensitivity to fludioxonil. For example, laboratory and field isolates of A. brassicicola that were highly resistant to iprodione and fludioxonil were separated into two groups based on their response to osmotic stress, with one group being highly sensitive and the other group being moderately sensitive to osmotic stress when grown on agar media amended with $40 \mathrm{~g}$ of $\mathrm{NaCl} /$ liter (2). At the same concentration of osmoticum, field isolates of A. alternata moderately resistant to fludioxonil were only slightly more sensitive to osmotic stress than were sensitive isolates (8). Similarly, Fujimura et al. (15) classified osmosensitive $o s-1 \mathrm{mu}-$ tants of $N$. crassa into two groups, and the group that was highly resistant to fludioxonil was less sensitive to osmotic stress than the group with moderate resistance to fludioxonil. These findings and the results presented in our study indicate that in a number of

TABLE 2. Effect of amino acids and DL-homocysteine on in vitro sensitivities of Botrytis cinerea and Penicillium digitatum to the anilinopyrimidine fungicides cyprodinil and pyrimethanil

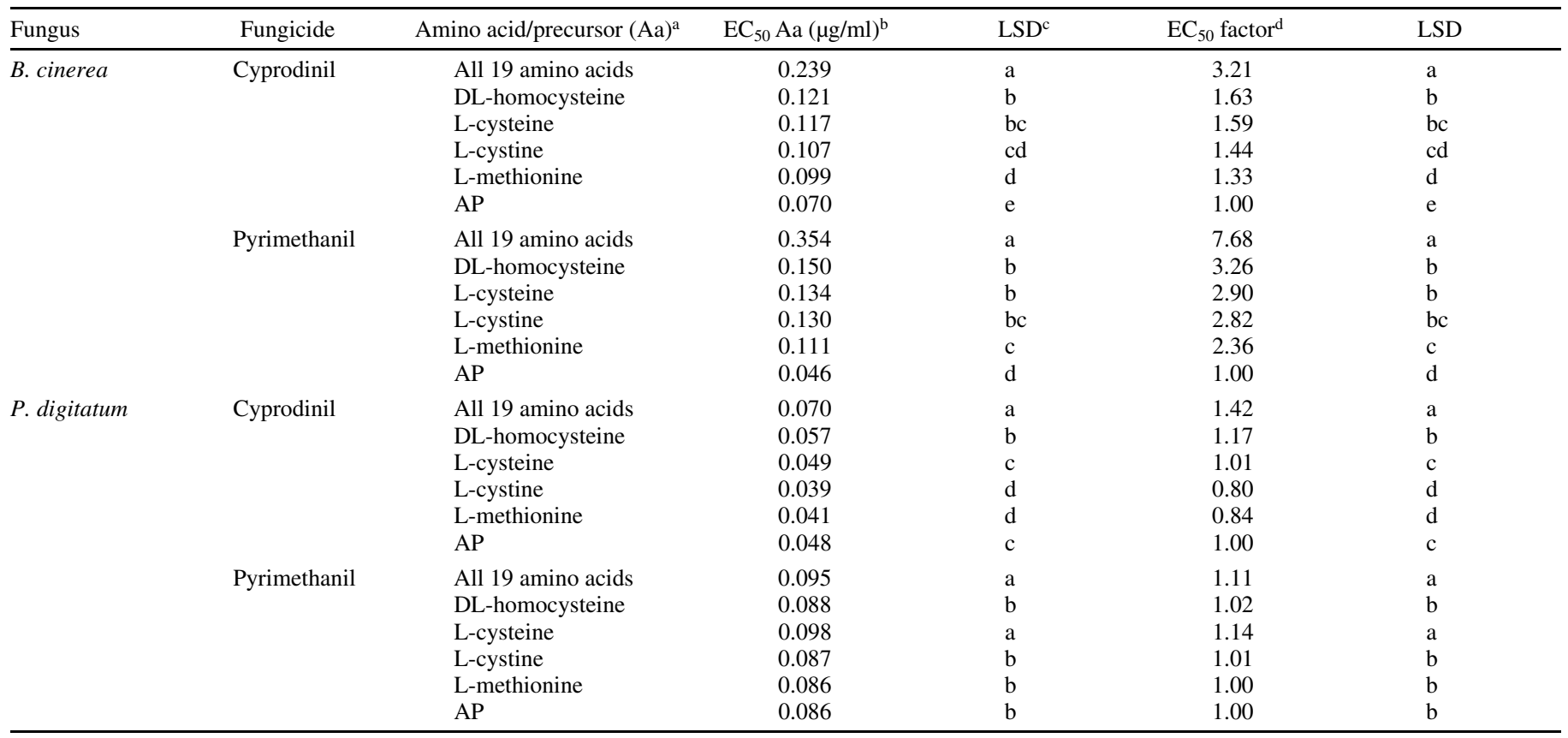

a The 19 amino acids used were: L-alanine, L-arginine, L-asparagine, L-cysteine, L-cystine, L-glutamine, L-glycine, L-histidine, L-isoleucine, L-leucine, L-lysine, L-methionine, L-phenylalanine, L-proline, L-serine, L-threonine, L-tryptophan, L-tyrosine, and L-valine. Amino acids were used at a concentration of $100 \mu \mathrm{M}$, while DL-homocysteine was used at $1,000 \mu \mathrm{M}$. The anilinopyrimidine (AP) minimal medium $(14,21)$ was used as culture medium.

${ }^{b}$ Effective concentrations of the fungicide that inhibit $50 \%$ of mycelial growth $\left(\mathrm{EC}_{50}\right)$ are averages from three experiments.

${ }^{c}$ Values followed by the same letter are not significantly different $(P>0.05)$ following a general linear model analysis and least significant difference (LSD) mean separation procedures.

${ }^{\mathrm{d}} \mathrm{EC}_{50}$ factor is defined as the ratio of the $\mathrm{EC}_{50}$ value in the presence of the tested amino acid or precursor to the $\mathrm{EC}_{50}$ value when the $\mathrm{AP}$ medium was used with no added amino acids. A factor of 1 was assigned to the fungal response to each fungicide on AP medium. 
fungal species osmotic stress tolerance is not clearly correlated with the degree of fludioxonil-resistance.

To evaluate additional osmoregulation-related resistance mechanisms that have been established for other fungi, we characterized the $\mathrm{N}$-terminal repeat region of the os-1-related twocomponent $\mathrm{HK}$ gene $(\mathrm{Pd} o s-1)$ from isolates of $P$. digitatum. In $N$. crassa and other fungi such as A. alternata, A. brassicicola, A. nidulans, B. fuckeliana, C. albicans, Cochliobolus heterostrophus, C. lagenarium, N. crassa, M. fructicola, and M. grisea this gene and its homologues have been shown to function as an osmosensor that regulates several MAP kinases that are involved in glycerol synthesis during osmotic stress conditions $(2,6,8$, $16,32,37,41,51)$. Diverse mutational changes that are located mainly in the motif with the six tandem repeats of 90 amino acids at the $\mathrm{N}$-terminal end of these genes have been found to be responsible for osmotic sensitivity as well as resistance to phenylpyrroles and dicarboximides $(2,6,8,37)$. In our sequence analysis of this genomic region of $P$. digitatum and comparisons with sequences from $M$. fructicola, B. cinerea, A. alternata, and $N$. crassa we found a high homology to the group III HK genes (5) of these latter fungi. Although nucleotide substitutions and subsequent amino acid changes were found at codons 314 and 392 among $P$. digitatum isolates, there were no consistent differences between fludioxonil-sensitive and MR and HR isolates of the fungus. It cannot be ruled out that mutations occur downstream of the repeat region in the HK gene or in other genes that encode components of the MAP kinase cascade in P. digitatum. In some filamentous ascomycete fungi several or many HKs are found, for example at least 13 to 15 in A. fumigatus, 21 in $C$. heterostrophus, and 20 in B. fuckeliana (5), but mutation of the $o s-1$-like gene alone leads to osmotic sensitivity in all cases tested. If multiple genes also exist in P. digitatum, it is possible that the redundancy of this family of genes or another independent osmo-regulatory system may be responsible for the wild-type-like phenotype of the HR isolates of $P$. digitatum in the presence of high concentrations of sodium chloride (Table 1).

OS-2 related MAP kinases are the last components in the phosphorelay of the osmoregulation pathway before glycerol production. These pathways have been studied in detail in $N$. crassa (i.e., OS) and S. cerevisiae (i.e., HOG). OS-2 related kinases are activated at high osmolarity by phosphorylation, leading to increased transcription of enzymes involved in glycerol synthesis. Phosphorylation of these kinases also occurs in fludioxonil-sensitive isolates of fungi in the presence of fludioxonil as shown for $C$. lagenarium and $C$. heterostrophus $(32,51)$, but not in fludioxonil-resistant isolates as shown in os-2 mutants of $N$. crassa (52) indicating a role for this gene in fludioxonil resistance. Thus, phenylpyrroles are thought to hyperactivate the osmotic response pathway by over-stimulating OS-2, leading to over-accumulation of intracellular glycerol (52).

In our immuno-detection studies with $P$. digitatum, phosphorylated OS-2 related kinase (PdOS-2) was significantly increased in both fludioxonil-sensitive and -resistant isolates after exposure to fludioxonil as compared to nonexposed mycelia. Thus, there was no qualitative difference in response among the isolates. Quantitatively, however, more phosphorylated PdOS-2 was found in the two sensitive isolates compared with MR and HR isolates. These results correlated in part with measurements of glycerol concentration in mycelia of the fungus. Thus, the amount of glycerol was higher for the fludioxonil-sensitive isolate compared with the MR and HR isolates. After exposure to fludioxonil, a similar significant increase in glycerol was detected in fludioxonil-sensitive $P$. digitatum and $N$. crassa isolates, indicating that fludioxonil activates the hyperosmotic response. Glycerol content also increased significantly in the MR isolate of $P$. digitatum, but not in the $\mathrm{HR}$ isolate. We also confirmed the involvement of the OS-2 MAP kinase in $N$. crassa, because the glycerol concentration did not increase in the $o s-2$ mutant after exposure to fludioxonil. The low levels of glycerol in the MR and HR isolates of $P$. digitatum, however, were not reflected by increased sensitivity to high salt concentrations. In our osmotic stress studies, growth was $40.6,46.7$, and $24.5 \%$ at $10 \mathrm{~g}$ of $\mathrm{NaCl} /$ liter, and $6.1,13.3$, and $3.5 \%$ at $40 \mathrm{~g}$ of $\mathrm{NaCl} /$ liter for the sensitive, MR, and HR isolates, respectively. Therefore, our results also indicate that glycerol is not the primary cytoplasmic osmoregulatory compound in P. digitatum. Other polyols such as mannitol or carbohydrates such as trehalose that are commonly found in fungi (18) may be involved in osmotic stress regulation in $P$. digitatum.

In summarizing our studies with fludioxonil and $P$. digitatum, we conclude that the mode of action of the fungicide in $P$. digitatum is the MAP kinase pathway that affects glycerol synthesis. Glycerol levels are increased in fludioxonil-sensitive isolates in the presence of fludioxonil to levels that are likely fungitoxic. In MR isolates, lower levels of glycerol are found in the absence of fludioxonil as compared to sensitive isolates. After fludioxonil exposure, the glycerol concentration is proportionally increased similar to the sensitive isolates. The increase in glycerol, however, is regulated and final levels do not reach toxic concentrations. In HR isolates, too, lower levels of glycerol are found in the absence of fludioxonil as compared to sensitive isolates, but no increase in glycerol concentration is found after fludioxonil exposure. Because OS-2 activity followed a similar pattern as in N. crassa os-2 mutants, similar target sites may be involved in both fungi. In MR and HR $P$. digitatum isolates, however, OS-2 activity is also reduced in the absence of fludioxonil. Therefore, the mitogen-activated protein kinase pathway in these resistant isolates may be under general repression either by a nonlethal mutation or a regulator gene between $o s-1$ and $o s-2$, or by an external regulator gene of the kinase pathway. The increased levels of phosphorylated OS-2 in the HR isolates after exposure to fludioxonil (as indicated by the immuno-blot analysis) indicate that the kinase pathway is functional and thus, perhaps more likely a regulator gene is the primary target of fludioxonil. Regulation upstream of $o s-2$ is currently being studied in N. crassa and other fungi $(3,25)$. Kinases are involved in many physiological functions such as oxidative respiration, drug resistance, oxidative stress response, and somatic cell integrity $(3,25)$. The general suppression of this pathway in resistant isolates is supported by the fact that growth and sporulation of MR and HR isolates of $P$. digitatum were reduced as compared to the sensitive isolates. Similar effects on growth and sporulation of other fungi have also been noted (25) and perhaps oxidative stress instead of osmotic stress (3) is a more accurate description of the effect of the mitogen fludioxonil on $P$. digitatum.

Although AP fungicides have a broad spectrum of activity, they were initially introduced in the mid-1990s as botryticides (47). Thus, the majority of research towards the elucidation of their mode of action has been performed with B. cinerea. Several studies indicated that certain amino acids, particularly methionine and its precursors (DL-homocysteine, cystathionine $\beta$-lyase, and cystathionine $\gamma$-synthase) affect the toxicity of APs. Therefore, it was suggested that the use of complex, undefined culture media was not appropriate for the in vitro evaluation of APs. This led the FRAC-AP committee to propose the use of a synthetic medium free of amino acids in monitoring and resistance risk assessment of $B$. cinerea to AP fungicides. Our results with $B$. cinerea confirmed that the addition of amino acids or homocysteine to the fungicide-amended medium increased $\mathrm{EC}_{50}$ values and thus, partially overcame fungicide toxicity. Other research, however, has questioned the involvement of amino acids in the mode of action of APs fungicides. Sequence analysis of the cystathionine $\beta$-lyase and cystathionine $\gamma$-synthase genes (two genes involved in methionine biosynthesis) from sensitive and resistant isolates of $B$. cinerea did not show any differences (35). In addition, fungicide toxicity to $B$. cinerea is either only partially overcome, as in 
our studies, or only when the fungicide is used at concentrations greater than $5 \mu \mathrm{M}$ (i.e., $1 \mu \mathrm{g} / \mathrm{ml}$ ) as indicated by Fritz et al. (13). In our previous studies we found that mean $\mathrm{EC}_{50}$ values of $P$. digitatum for pyrimethanil using AP medium were significantly lower (i.e., $0.21 \mu \mathrm{g} / \mathrm{ml}$ ) compared with using PDA (i.e., $0.31 \mu \mathrm{g} / \mathrm{ml}$ ) (30). No significant differences, however, were observed in mycelial growth inhibition at $0.35 \mu \mathrm{g}$ of pyrimethanil $/ \mathrm{ml}$, the concentration where growth of the fungus on PDA was inhibited by $99 \%$. In the present study with $P$. digitatum, the addition of amino acids or homocysteine to AP agar significantly affected $\mathrm{EC}_{50}$ values of $P$. digitatum for cyprodinil and pyrimethanil. Compared with $B$. cinerea, however, $\mathrm{EC}_{50}$ factors were low (i.e., $\leq 1.42$ for cyprodinil, $\leq 1.14$ for pyrimethanil). This suggests that methionine biosynthesis is not the primary target site of APs in P. digitatum. Biochemical and microscopic studies have shown that pyrimethanil has little effect on the pre-penetration stages of $B$. cinerea, whereas later stages of pathogenesis were more severely affected, and the fungicide appeared to reduce host cell lysis and the expansion of infection sites (7). This indicates that the major effect of this class of fungicides, as demonstrated by Miura et al. (40) for the AP mepanipyrim, is probably based on the inhibition of secretion of extracellular host cell wall degrading enzymes that accumulate inside the treated fungal tissue.

In this study, we elucidated resistance mechanisms to fludioxonil and pyrimethanil in isolates of $P$. digitatum. Some differences in results were obtained as compared to other fungi where resistance mechanisms against these two classes of fungicides have been studied in detail. In previous investigations with fludioxonil, fungi used were mainly laboratory-induced mutants. Fludioxonil-resistant isolates were also obtained from field locations after dicarboximide applications and these isolates were less sensitive to both, dicarboximide and fludioxonil $(8,22)$. Isolates of $P$. digitatum used in our study were naturally occurring field isolates that were collected in citrus packinghouses. In contrast to field isolates of fungal species studied by others, these fludioxonil-resistant isolates were not selected after application of dicarboximide fungicides. Dicarboximides such as iprodione are not being used on citrus in California and, moreover, they are not effective in the control of green mold. In contrast, in all investigations on pyrimethanil resistance in the current and previous studies, field isolates were used $(38,39,40)$. Because fludioxonil and pyrimethanil only recently became registered on citrus and have not yet been widely utilized commercially, isolates of $P$. digitatum used in our study had not been subjected to any selection pressure to phenylpyrroles or APs. These basic differences in isolate origin as well as the different fungal species evaluated in the numerous investigations, possibly may explain some of the differences in the characterized responses we are describing for P. digitatum.

\section{ACKNOWLEDGMENTS}

This research was financially supported by the California Citrus Research Board and the Greek State Scholarships Foundation (I.K.Y.). We thank Bayer Crop Science, Janssen Pharmaceutica Inc., and Syngenta Crop Protection for technical and financial contributions. This research is part of a Ph.D. dissertation undertaken by L. Kanetis.

\section{LITERATURE CITED}

1. Atlas, R. M. 2004. Handbook of Microbiological Media. 3rd ed. L. C. Parks, ed. CRC Press, Boca Raton, FL.

2. Avenot, H., Simoneau, P., Iacomi-Vasilescu, B., and Betaille-Simoneau, N. 2005. Characterization of mutations in the two-component histidine kinase gene AbNIK1 from Alternaria brassicicola that confer high dicarboximide and phenylpyrrole resistance. Curr. Genet. 47:234-243.

3. Banno, S., Noguchi, R., Yamashita, K., Fukumori, F., Kimura, M., Yamaguchi, I., and Fugimura, M. 2007. Roles of putative His-to-Asp signaling modules HPT-1 and RRG-2, on viability and sensitivity to osmotic stresses in Neurospora crassa. Curr. Genet. 51:197-208.
4. Bus, V. G., Bongers, A. J., and Risse, L. A. 1991. Occurrence of Penicillium digitatum and P. italicum resistant to benomyl, thiabendazole, and imazalil on citrus from different geographic origins. Plant Dis. 75:10981100.

5. Catlett, N. L., Yoder, O. C., and Turgeon, B. G. 2003. Whole-genome analysis of two-component signal transduction genes in fungal pathogens. Eukaryot. Cell 2:1151-1161.

6. Cui, W., Beever, R. E., Parkes, S. L., Weeds, P. L., and Templeton, M. D. 2002. An osmosensing histidine kinase mediates dicarboximide resistance in Botryotinia fuckeliana (Botrytis cinerea). Fungal Genet. Biol. 36:187198.

7. Daniels, A., and Lucas, J. A. 1995. Mode of action of the anilinopyrimidine fungicide pyrimethanil. 1. In vivo activity against Botrytis fabae on broad bean (Vicia faba) leaves. Pestic. Sci. 45:33-41.

8. Dry, I. B., Yuan, K. H., and Hutton, D. G. 2004. Dicarboximide resistance in field isolates of Alternaria alternata is mediated by a mutation in a two-component hisitidine kinase gene. Fungal Genet. Biol. 41:102-108.

9. Eckert, J. W., and Eaks, I. L. 1989. Postharvest Disorders and Diseases of Citrus Fruit. Pages 179-260 in: The Citrus Industry, Volume V - Crop Protection, Postharvest Technology, and Early History of Citrus Research in California. W. Reuther, E. C. Calavan, and G. E. Carman, eds. University of California, Division of Agricultural and Natural Resources, Oakland, CA.

10. Errampalli, D. 2003. Effect of fludioxonil on germination and growth of Penicillium expansum and decay in apple cvs. Empire and Gala. Crop Prot. 23:822-827.

11. Förster, H., Driever, G. F., Thompson, D. C., and Adaskaveg, J. E. 2007. Postharvest decay management for stone fruit crops in California using the "reduced-risk" fungicides fludioxonil and fenhexamid. Plant Dis. 91:209-215.

12. Förster, H., Kanetis, L., and Adaskaveg, J. E. 2004. Spiral gradient dilution, a rapid method for determining growth responses and 50\% effective concentration values in fungus-fungicide interactions. Phytopathology 94:163-170.

13. Fritz, R., Lanen, C., Chapeland-Leclerc, F., and Leroux, P. 2003. Effect of the anilinopyrimidine fungicide pyrimethanil on the cystathionine $\beta$-lyase of Botrytis cinerea. Pestic. Biochem. Phys. 77:54-65.

14. Fujimura, M., Ochiai, N., Ichiishi, A., Usami, R., Horikoshi, K., and Yamaguchi, I. 2000. Sensitivity to phenypyrrole fungicides and abnormal glycerol accumulation in os and cut mutant strains of Neurospora crassa. J. Pestic. Sci. 25:31-36.

15. Fujimura, M., Ochiai, N., Ichiishi, A., Usami, R., Horikoshi, K., and Yamaguchi, I. 2000. Fungicide sensitivity and osmotic stress sensitivity in os mutants of Neurospora crassa. Pestic. Biochem. Phys. 67:125-133.

16. Furukawa, K., Katsuno, Y., Urao, T., Yabe, T., Yamada-Okabe, T., Yamada-Okabe, H., Yamagata, Y., Abe, K., and Nakajima, T. 2002. Isolation and functional analysis of a gene, $\operatorname{tcs} B$, encoding a transmembrane hybrid-type histidine kinase from Aspergillus nidulans. Appl. Environ. Microbiol. 68:5304-5310.

17. Gehmann, K., Nyfeler, R., Leadbeater, A. J., Nevill, D., and Sozzi, D. 1990. CGA 173506: A new phenylpyrrole fungicide for broad-spectrum disease control. Brighton Crop Prot. Conf. Pests Dis. 2:399-406.

18. Griffin, D. H. 1994. Fungal Physiology. 2nd ed. Wiley-Liss, Inc., New York, NY.

19. Hilber, U. W., and Hilber-Bodmer, M. 1996. Genetic basis and monitoring of resistance of Botryotinia fuckeliana to anilinopyrimidines. Plant Dis. 82:496-500.

20. Hilber, U. W., and Schüepp, H. 1996. A reliable method for testing the sensitivity of Botryotinia fuckeliana to anilinopyrimidines in vitro. Pestic. Sci. 47:241-247.

21. Holmes, G. J., and Eckert, J. W. 1999. Sensitivity of Penicillium digitatum and $P$. italicum to postharvest citrus fungicides in California. Phytopathology 89:716-721.

22. Iacomi-Vasilescu, B., Avenot, H., Betaile-Simoneau, N., Laurent, E., Guenard, M., and Simoneau, P. 2004. In vitro sensitivity of Alternaria species pathogenic to crucifers and identification of Alternaria brassicicola field isolates highly resistant to both dicarboximides and phenylpyrroles. Crop Prot. 23:481-488.

23. Irmler, S., Rogniaux, H., Hess, D., and Pillonel, C. 2006. Induction of OS-2 phosphorylation in Neurospora crassa by treatment with phenylpyrrole fungicides and osmotic stress. Pestic. Biochem. Phys. 84:25-37.

24. Jespers, A. B. K., and de Waard, M. A. 1995. Effect of fenpiclonil on phosphorylation of glucose in Fusarium sulphureum. Pestic. Sci. 44:167175 .

25. Jones, C. A., Greer-Phillips, S. E., and Borkovich, K. A. 2007. The response regulator RRG-1 functions upstream of a MAPK pathway impacting asexual development, female fertility, osmotic stress and fungicide resistance in Neurospora crassa. Mol. Biol. Cell 18:2123-2136.

26. Judelson, H. S. 1996. Genetic and physical variability at the mating type 
locus of the oomycete, Phytophthora infestans. Genetics 144:1005-1013.

27. Kanetis, L., and Adaskaveg, J. E. 2005. Resistance potential of azoxystrobin, fludioxonil, and pyrimethanil, to the citrus postharvest pathogen Penicillium digitatum. (Abstr.) Phytopathology 95(suppl.):S51.

28. Kanetis, L., Förster, H., and Adaskaveg, J. E. 2006. Fludioxonil-resistant isolates of Penicillium digitatum show diverse fitness and no relationship to osmotic stress regulation. (Abstr.) Phytopathology 96(suppl.):S58.

29. Kanetis, L., Förster, H., and Adaskaveg, J. E. 2007. Comparative efficacy of the new postharvest fungicides azoxystrobin, fludioxonil, and pyrimethanil for managing citrus green mold caused by Penicillium digitatum. Plant Dis. 91:1502-1511.

30. Kanetis, L., Förster, H., and Adaskaveg, J. E. 2007. Baseline sensitivities for new postharvest fungicides against Penicillium spp. on citrus and multiple resistance evaluations in P. digitatum. Plant Dis. (In Press.)

31. Kinay, P., Mansour, M. F., Mlikota-Gabler, F., Margosan, D. A., and Smilanick, J. L. 2007. Characterization of fungicide-resistant isolates of Penicillium digitatum collected in California. Crop Prot. 26:647-656.

32. Kojima, K., Takano, Y., Yoshimi, A., Tanaka, C., Kikuchi, T., and Okuno, T. 2004. Fungicide activity through activation of a fungal signaling pathway. Mol. Microbiol. 53:1785-1796.

33. Krystofova, S., and Borkovich, K. A. 2005. The heterotrimeric G-protein subunits GNG-1 and GNB-1 form a G $\beta \gamma$ dimer required for normal female fertility, asexual development, and $\mathrm{G \alpha}$ protein levels in Neurospora crassa. Eukaryot. Cell 4:365-378.

34. Latorre, B. A., Spadaro, I., and Rioja, M. E. 2002. Occurrence of resistant isolates of Botrytis cinerea to anilinopyrimidine fungicides in table grapes in Chile. Crop Prot. 21:957-961.

35. Leroux, P., Fritz, R., Debieu, D., Albertini, C., Lanen, C., Bach, J., Gredt, M., and Chapeland, F. 2002. Mechanisms of resistance to fungicides in field strains of Botrytis cinerea. Pest Manag. Sci. 58:876-888.

36. Leroux, P., and Gredt, M. 1996. In vitro methods for monitoring pyrimethanil resistance of Botrytis cinerea in grapevine. EPPO Bull. 26:186188.

37. Ma, Z., Luo, Y., and Michailides, T. 2006. Molecular characterization of the two-component histidine kinase gene from Monilinia fructicola. Pest Manag. Sci. 62:991-998

38. Masner, P., Muster, P., and Schmid, J. 1994. Possible methionine biosynthesis inhibition by pyrimidinamine fungicides. Pestic. Sci. 42:163166.

39. Milling, R. J., and Richardson, C. J. 1995. Mode of action of the anilinepyrimidine fungicide pyrimethanil. Effects on enzyme secretion in Botrytis cinerea. Pestic. Sci. 45:43-48.

40. Miura, I., Kamakura, T., Maeno, S., Hayashi, S., and Yamaguchi, I. 1994.
Inhibition enzyme secretion in plant pathogens by mepanipyrim, a novel fungicide. Pestic. Biochem. Phys. 48:222-228.

41. Motoyama, T., Ohira, T., Kadokura, K., Ichiishi, A., Fujimura, M., Yamaguchi, I., and Kudo, T. 2005. An Os-1 family histidine kinase from a filamentous fungus confers fungicide-resistance to yeast. Curr. Genet. 47:298-306.

42. Ochiai, N., Fujimura, M., Motoyama, T., Ichiishi, A., Usami, R., Horikoshi, K., and Yamaguchi, I. 2001. Characterization of mutations in the two-component histidine kinase gene that confer fludioxonil resistance and osmotic sensitivity in the os-1 mutants of Neurospora crassa. Pest Manag. Sci. 57:437-442.

43. Okada, A., Banno, S., Ichiishi, A., Kimura, M., Yamaguchi, I., and Fujimura, M. 2005. Pyrrolnitrin interferes with osmotic signal transduction in Neurospora crassa. J. Pestic. Sci. 30:378-383.

44. Orth, A. B., Rzhetskaya, M., Pell, E. J., and Tien, M. 1995. A serine (threonine) protein kinase confers fungicide resistance in the phytopathogenic fungus Ustilago maydis. Appl. Environ. Microbiol. 61:23412345.

45. Oshima, M., Fujimura, M., Banno, S., Hashimoto, C., Motoyama, T., Ichiishi, A., and Yamaguchi, I. 2002. A point mutation of the twocomponent histidine kinase $B c O S-1$ gene confers dicarboximide resistance in field isolates of Botrytis cinerea. Phytopathology 92:75-80.

46. Pillonel, C., and Meyer, T. 1997. Effect of phenylpyrroles on glycerol accumulation and protein kinase activity of Neurospora crassa. Pestic. Sci. 49:229-236.

47. Rosslenbloich, H. J., and Stuebler, D. 2000. Botrytis cinerea - History of chemical control and novel fungicides for its management. Crop Prot. 19:557-561.

48. Steel, C. C. 1996. Catalase activity and sensitivity to the fungicides, iprodione and fludioxonil in Botrytis cinerea. Lett. Appl. Microbiol. 22:335-338.

49. Vignutelli, A., Hilber-Bodmer, M., and Hilber, U. W. 2002. Genetic analysis of resistance to the phenylpyrrole fludioxonil and the dicarboximide vinclozolin in Botryotinia fuckeliana. Mycol. Res. 106:329-335.

50. Vogel, H. J. 1964. Distribution of lysine pathways among fungi: Evolutionary implications. Am. Nat. 98:435-446.

51. Yoshimi, A., Kojima, K., Takano, Y., and Tanaka, C. 2005. Type III histidine kinase is a positive regulator of Hog1-type mitogen-activated protein kinase in filamentous fungi. Eukaryot. Cell 4:1820-1828.

52. Zhang, Y., Lamm, R., Pillonel, C., Lam, S., and Xu, J. R. 2002. Osmoregulation and fungicide resistance: The Neurospora crassa os-2 gene encodes a HOG1 mitogen-activated protein kinase homologue. Appl. Environ. Microbiol. 68:532-538. 